\title{
On the criticism of the determination of net energy with difference trials
}

\author{
A. J. H. VAN ES \\ Laboratory of Animal Physiology, Agricultural University, Wageningen, Netherlands
}

\section{Summary}

Five kinds of criticism on the determination of net energy with difference trials are discussed. It is concluded that some caution is needed in the interpretation of the results of such trials, especially of those in which the testfood and the basal ration are not of equal composition. Although KELLNER used the latter type of difference trial to establish his starch-equivalent theory, it is considered that in general the starch-equivalent values and the feeding standards expressed in starch equivalent are approximately correct since the starch value appears to be a replacement value and since the requirements have been determined under circumstances comparable to those prevailing in practice. More information, however, is needed on the requirements of the animals and especially on the starch-equivalent content of roughage. A description is given of a method with which this might be obtained.

\section{Introduction}

The net-energy content of a food or a ration is usually determined in a difference trial, each trial consisting of two or three parts. During the first part the animal receives only the basal ration; often, with the aim to obtain a higher accuracy, after the second part the experiment with the basal ration is repeated. The basal ration is given in such an amount that the animal which should be healthy, fullgrown, nonlactating and non-pregnant, is fed slightly more than its maintenance requirement of metabolisable energy. Moreover, this ration should not be deficient in either protein, minerals or vitamins. During the second part the experimental animal is fed a basal ration together with a quantity of the food of which the net-energy content is to be determined. In this part of the trial the higher amount of metabolisable energy will result in a deposition of fat and a little protein. The difference between the second and the first and/or third part in intake of metabolisable energy is compared with the difference in energy balance. Both differences are usually said to be due to the testfood. Corrections may be applied if there was a depression of the digestibility or an increased body weight in the second part.

Much criticism has been heard ever since the difference-trial method to determine net energy exists; this is treated in the following sections.

\section{Interaction between basal ration and testfood}

There is doubt whether during its second part the metabolisable energy of the basal ration is utilized to the same extent as in the first or third and whether the utiliza-

Received for publication 2nd November, 1962. 
tion of the metabolisable energy of the testfood also depends on the make-up of the basal ration. For monogastric animals the major part of the absorbed energy consists of the energy in protein, in fat and in carbohydrates. It is difficult to understand how these substances, if resulting from a mixture of basal ration and testfood, may be utilized more or less efficiently than with the average efficiency of utilization of basal ration and testfood when fed alone, if no deficiencies occur unless the animal uses some components of the mixture by preference for maintenance or for production. With ruminants combinations of basal ration and testfood may alter the microbiological events in the rumen so that the fermentation on such a mixture is not the average of the fermentations of basal ration and of testfood when fed alone. Most investigators include a small amount of the testfood in the basal ration to stimulate growth of bacteria which prefer the testfood. Whether it is effective or correct, is questionable.

\section{Constant efficiency of utilization of the metabolisable energy at various levels above maintenance}

Also for quite a long time the problem has been discussed whether according to the law of diminishing returns higher quantities of the testfood would be utilized with

\section{CORRIGENDUM}

to Neth. J. agric. Sci., Vol. 11 No. 1, February 1963

Owing to an unfortunate printing error on page 39 of our last issue, line 11 from the bottom should be replaced by :

bolisable energy of the mixture by preference for either production or maintenance,

second part of the trial the mixture of both foods is utilized both for maintenance and for production. Recent studies (BLAXTER, 1962) have shown that the efficiency with which in ruminants the metabolisable energy is utilized for maintenance, is higher and varies less from one food to another than the efficiency with which it is utilized for fat production. Thus, unless the animal does use a part of the meta(1961) found the same for whole rations for levels up to 2,4 times maintenance the metabolisable energy of the mixture will be utilized for maintenance nearly as effectively as the metabolisable energy of the basal ration. For production, however, the remainder of the metabolisable energy of the mixture will be utilized with the average efficiency (AE) of utilization of basal ration and testfood, i.e. in general not with the efficiency (SE) of the testfood if fed alone. AE and SE will differ more when the efficiencies of utilization of the metabolisable energy for fat synthesis of testfood and basal ration, each fed alone, differ more, and also when smaller quantities of the testfood are used. This theory implies too that for difference experiments with testfoods differing from the basal ration the efficiency of the utilization for fat synthesis depends on the amount of the testfood since the ratio testfood/ 
basal ration of the mixture increases if more testfood is given. This, however, seems to be in conflict with the results of NeHring et al. mentioned above. In their experiments with adult steers two and three $\mathrm{kg}$ respectively of the testfood (barley) was given, while the basal ration consisted of hay $(72 \%)$ and a concentrate mixture $(28 \%)$. It may have been that the two quantities of barley differed too little to obtain a significant increase or decrease in utilization. In their experiments with sheep the basal ration consisted of only hay $(800 \mathrm{~g})$ and the testfood was barley given in various amounts from 100 up to $700 \mathrm{~g}$. In this case the good quality of the artificially dried hay and/or interaction between testfood and basal ration may have obscured the expected increase of the efficiency for higher amounts of the testfood. In their experiments with pigs the testfood (barley) and the basal ration (a concentrate mixture) would have given about the same efficiency of utilization for fat synthesis if each had been fed alone. It is well known that it is very difficult to detect small differences in utilization percentages since these percentages are never free from a considerable error, especially if the testfood only gives a small increase in energy balance.

If, however, the animal utilizes some components of the mixture by preference for maintenance or production, then also it is not correct to say that only the testfood caused the increased energy balance. In this case it is impossible to say which part of the basal ration and which part of the testfood is utilized for maintenance or for production.

\section{Constant proportion of efficiencies of utilization for fat synthesis, milk production and maintenance}

Recently GüTTE (1962) has suggested that, if the difference-trial determination of net energy were sound, the efficiencies of the utilization of the metabolisable energy for body fat or milk production of various foods should be in proportion to their efficiencies of the utilization for maintenance. This forms a fourth criticism as experiments of BLAXTER (1961) have clearly shown that the metabolisable energy of quite a variety of foodstuffs are almost uniformly utilized for maintenance. KELLNER, however, found that the utilization for body-fat production varied a great deal for foodstuffs such as concentrates on the one hand and hay or straw on the other. GürTe has explained this opinion in the following way. We suppose $A$ and $B$ to be quantities of kcal metabolisable energy of feeds $A$ and $B$, each just sufficient for the maintenance requirement of our experimental animal. We restrict ourselves to synthesis of body fat and maintenance. In this connection it makes little difference whether body fat or milk is produced. First $A$ is fed, next $B$ and afterwards $A+B$, giving energy balances $P_{1}=0 \mathrm{kcal}, P_{2}=0 \mathrm{kcal}$ and $P_{3}=P_{3} \mathrm{kcal}$ respectively. During fasting the animal had an energy balance of $-V$ kcal. According to the difference-trial technique the percentage of the utilization of $A$ for fat production is $\frac{P_{3}}{A} \times 100$, and of $B \frac{P_{3}}{B} \times 100$. The percentages of the utilization of $A$ and $B$ for maintenance obviously are $\frac{V}{A} \times 100$ and $\frac{V}{B} \times 100$, therefore $\frac{P_{3}}{A}: \frac{P_{3}}{B}=\frac{V}{A}: \frac{V}{B}$. The example, however, is a special case. It will even be obtained if there is considerable interaction between $A$ and $B$ in the third experiment. In that case only $P_{3}$ will have another value, but the ratio $\frac{P_{3}}{A}: \frac{P_{3}}{B}$ remains equal. We repeat the experiment with 
the rations $A$ and $B$, but do not give $A, B$ and $A+B$, but $1 \frac{1}{2} A, 1 \frac{1}{2} B$ and $1 \frac{1}{2} A$ $+1 \frac{1}{2} B . P_{1}$ and $P_{2}$ now of course are positive. The utilization percentages for fat production are $\frac{P_{3}-P_{2}}{1 \frac{1}{2} A} \times 100$ and $\frac{P_{3}-P_{1}}{1 \frac{1}{2} B} \times 100$, those for maintenance $\frac{V}{A} \times 100$ and $\frac{V}{B} \times 100 . \quad \frac{P_{3}-P_{2}}{1 \frac{1}{2} A}: \frac{P_{3}-P_{1}}{1 \frac{1}{2} B}$ will be equal to $\frac{V}{-A}: \frac{V}{B}$, if $P_{1}=P_{2}$ which only will be the case, if $\frac{P_{1}}{\frac{1}{2} A}=\frac{P_{3}-P_{2}}{1 \frac{1}{2} A}$ and $\frac{P_{2}}{\frac{1}{2} B}=\frac{P_{3}-P_{1}}{1 \frac{1}{2} B}$, i.e. if the efficiency of the utilization for fat synthesis in the experiment with $1 \frac{1}{2} A$ or $1 \frac{1}{2} B$ is equal to that of $1 \frac{1}{2} A$ or $1 \frac{1}{2} B$ in the experiment with the mixed ration. This presupposes constant efficiency of utilization of the metabolisable energy at all levels of intake above maintenance and independency of the efficiency from basal ration or from interaction between basal ration and testfood.

If we feed in another experiment $1 \frac{1}{2} A, B$ and $1 \frac{1}{2} A+B, \frac{P_{3}}{1 \frac{1}{2} A}: \frac{P_{3}-P_{2}}{B}$ will only be equal to $\frac{V}{A}: \frac{V}{B}$, if $\frac{2}{3} P_{3}=P_{3}-P_{1}$ or $P_{1}=\frac{1}{3} P_{3}$. If we feed $1 \frac{1}{2} A, \frac{2}{3} B$ and $1 \frac{1}{2} A+\frac{2}{3} B$, i.e. quantities of the basal ration $\left(1 \frac{1}{2} A\right)$ and the testfood $\left(\frac{2}{3} B\right)$ often used in difference trials, $P_{2}$ will be negative. An addition of $\frac{1}{3} A$ as well as an $\underset{P_{3}}{\text { addition of }} \frac{1}{3} B$ would reduce this negative balance to zero. Therefore we get $\frac{P_{3}-P_{2}}{1 \frac{1}{A}}$ $=\frac{P_{3}}{7 / 6 \mathrm{~A}}$ and $\frac{P_{3}}{7 / 6 \mathrm{~A}}: \frac{\mathrm{P}_{3}-P_{1}}{2 / 3 \mathrm{~B}}$ will be equal to $\frac{V}{A}: \frac{V}{B}$, if $P_{3}=\frac{7}{3} P_{1}$. Also in these two experiments the conditions $P_{1}=\frac{1}{3} P_{3}$ and $P_{1}=\frac{3}{7} P_{3}$, respectively, only will be fulfilled, if the same assumptions are made as in the experiment with $1 \frac{1}{2} \mathrm{~A}$ and $1 \frac{1}{2} B$. In the beginning of this section we have seen that experimental evidence is in conflict with at least one of these assumptions.

\section{Correction for change in body weight}

A last criticism deals with the value of the correction for change in body weight of the animal in the course of the difference trial. This change is partly due to a change in empty-body weight and partly to difference in fill of the gastrointestinal tract. It is not accurately known to which degree either of these changes influences the maintenance metabolism and thus the energy balance.

\section{Discussion}

Summarizing we may conclude that the results of difference experiments should be interpreted with caution, especially if basal ration and testfood differ in composition. As all Kellner's experiments on starch equivalent have been performed in the latter way, one might doubt the value of the starch-equivalent theory on which our Netherland feeding standards for ruminants are based. In KellNER's system one starch equivalent of all feeds - both of concentrates and of roughages - just as one $\mathrm{kg}$ digestible starch should give a fat synthesis of about $2360 \mathrm{kcal}$, if measured with an adult steer in a difference trial with a basal ration of about $50 \%$ hay of good quality, some dried sugar beet pulp and a concentrate mixture. Starch equivalents may therefore be considered to be replacement equivalents (KLEIBER, 1961). We prefer 
this concept because, even if one or more of the criticisms mentioned above were correct, the replacement values would be reliable, although all difference trials would have a systematic error of about the same size in the same direction. This of course holds true especially for such values of foods differing less in composition from starch. The fact that there is no between-animal variation in the efficiency of the utilization of the metabolisable energy for fat synthesis (NEHRING et al., 1958, 1960, 1961) simplifies the interpretation of results of difference trials obtained with different animals of the same species. This and the fact that the efficiency of the utilization does not change considerably with time is demonstrated by experiments at Rostock (HoFFMANN et al., 1962) in which after 60 years with other animals (steers) with another basal ration (although of the same make-up) starch and protein gave the same production of energy in body fat as was found by Kellner. Kellner and Fingerlino, however, performed very few experiments with hay, silage and mixed rations. Since their trials the way of hay-making has improved considerably. Therefore especially in this field more knowledge is needed.

Also the criticism that KellNeR's system was derived with and meant for fat production and therefore should not be applied to maintenance, lactation or growth is not very strong. Most experiments to determine the requirements of the animals have been done with rations which had a make-up differing not very much from those used in practice in the country where such experiments were initiated. If the computed starch equivalents of the components of these experimental rations were incorrect (because of interaction between some components of the ration different from the interaction between each of these components alone and the basal ration in a difference trial, by different efficiencies in the utilization for maintenance, growth, milk or body-fat production or by decreasing efficiency at very high levels of milk production), then the same would be the case with the rations composed by the farmers in a not too different way. In general therefore the requirements of the animals on the farm would be met approximately. More knowledge about the requirements is, however, needed. There is some difference between the rations used for lactating cows in the Netherlands (fairly large amounts of hay and silage together with concentrates) and those used by FreDERIRSEN (1931) (rather large amounts of straw and beets together with concentrates and some hay) on whose experiments the present feeding standards are mainly based. Also in most experiments to determine the requirement a change in energy balance was not actually measured, but estimated from a change in body weight and the content of starch equivalent of the rations was computed from their chemical composition or from their content of digestible components and crude fibre in stead of measured with difference trials. Such experiments performed in the Netherlands showed that present feeding standards used there have an accuracy which is sufficient for practical purposes under the conditions prevailing in this country.

Reliable values of the starch-equivalent content of hay and silage with difference trials are difficult to obtain. The animals often do not eat these materials in sufficient amount, especially if the quality is low. Therefore the difference in energy balance is small and its error large in proportion to the difference itself. With hay of low quality the results will never be reliable. With good hay or with silage at least six experiments, each with two periods in which the basal ration and one in which the basal ration and the testfood are fed (altogether lasting 18 weeks), are needed (SchirmanN et al., 1961). 
Energy-balance experiments to determine the requirements are less difficult and cumbersome, although between-animal variation in maintenance requirement and insufficient knowledge of the starch-equivalent content of the components of the ration do not simplify the interpretation of the results. One experiment with one animal may last $6-7$ weeks and its energy balance will have a standard deviation of about $2 \%$ of the intake of metabolisable energy (intake of metabolisable energy $37.000 \mathrm{kcal}$, energy in milk $15.000 \mathrm{kcal}$, heat production $22.000 \mathrm{kcal}$, standard deviation of these items if determined in an experiment : $1 \%=370 \mathrm{kcal}, 3 \%=450 \mathrm{kcal}$ and $2 \%$ $=440 \mathrm{kcal}$ respectively; standard deviation of energy balance: $\sqrt{370^{2}+450^{2}+440^{2}}$ $=730 \mathrm{kcal}$; the high standard deviation for heat production probably includes between-experiment variation, i.e. when these experiments are repeated with the same animal and the same ration after intervals of several months). The interpretation of the results may be made easier if experiments with a variety of rations are performed one after the other with the same animal during and after lactation, i.e. both at the production and maintenance level as was done by MøLLGAARD. A fairly accurate estimate of the starch-equivalent content of the concentrate part of the ration might be obtained from the values obtained in difference trials by KELLNER and FingerLing in Möckern and, nowadays in Rostock, by NeHRING and collaborators. Also in Rostock the make-up of the basal ration differs little from that used in Möckern. Similar values for the roughage part might be computed with the method of KeLLNER or of Hoffmann et al. (1960) from the content of digestible nutrients and of crude fibre, data which might be determined in digestibility trials with sheep. As such computations will only give rough approximations, it would be better to determine the starch -equivalent value of at least one roughage in an actual difference trial.

The combination of difference trials and requirement experiments would also give the possibility to determine the starch-equivalent value of roughage of bad quality since in the latter experiments the hay of which the starch equivalent had been determined in a difference trial, might be replaced by hay of other quality. The inevitable, necessary change of the protein content of the concentrate part of the ration to restore the protein content of the ration would probably not alter the efficiency of the utilization of the concentrate part. At the same time three non-lactating animals might be used for the difference trials and three lactating cows for the requirement experiments. Preliminary and experimental periods might each last three weeks; six respiration experiments of 24 hours might be performed per animal per experimental period in one of two respiration chambers. In the experiments 1,3 and 5 of the difference trial a basal ration is fed, in experiments 2 and 4 the same basal ration plus roughage $A$ of which the starch equivalent is to be determined. In the experiments 1,3 and, if necessary, 5 with the 3 lactating animals a ration consisting of the roughage $A$ and concentrates is used, in the experiments 2 and 4 the roughage $A$ is replaced by other roughages $B, C$ etc. not used in the difference trial. If necessary in these experiments the concentrate ration should be slightly changed in regard to its content of digestible crude protein. For higher accuracy the lactation experiments might be performed as reversal trials. After lactation in other experiments the non-pregnant animals are given rations equal in composition to the lactation rations, but in an amount just sufficient for maintenance. The difference trial gives an estimate of the starch equivalent of the roughage $A$, the lactation experiments give estimates of the starch equivalent of the roughages $B$ and $C$ and in combination with the maintenance experiments estimates of the requirements of lactating and non-lactating animals. 
ON THE CRITICISM OF THE DETERMINATION OF NET ENERGY WITH DIFFERENCE TRIALS

\section{I T ER A T UR E}

BLAXTER, K. L.

1961 Proc. 2nd Symp. Energy Metab, Wageningen, 1961.

FREDERIKSEN, L.

1962 Triennial report of the Hannah Dairy Res. Inst., p. 32.

GüTTE, J. O.

1931 Beretning fr: Forsogslaboratoriet København. 136.

HOFFMANN, L., R. SCHIE-

1962 Zeitschr. f. Tierphys., Tierern. und Futtermittelk. 17, 107.

MANN and $K$. NeHRING

KLEIBER, $M$.

NeHRING, K., et al.

SchiemanN, R., L. HoFf-

1960 Archiv. f. Tierernährung. 10, 229; 11 (1962) 337.

1961 Proc. 2nd Symp. Energy Metab., Wageningen, 1961.

1958 Archiv f. Tierernährung. 9, $85 ; 10$ (1960) 275 ; 11 (1961) 157.

MANN and W. JENTSCH

1961 Proc. 2nd Symp. Energy Metab., Wageningen, 1961. 